\title{
PROCESSO DE SELEÇÃO DE PROJETOS NA GESTÃO DE PORTFÓLIO: \\ o caso de uma organização sem fins lucrativos
}

\author{
1-Fabrício Martins Lacerda \\ Mestre em Administração pela Universidade Nove de Julho (PMPA-GP/UNINOVE), Brasil. \\ fabriciomlacerda@gmail.com \\ http://lattes.cnpq.br/0029523718128927
}

\section{2-Cristina Dai Prá Martens}

Doutora em Administração pela Universidade Federal do Rio Grande do Sul (PPGA/EA/UFRGS), Brasil.

Professora do Programa de Pós-Graduação em Administração da Universidade Nove de Julho (PPGA/UNINOVE), Brasil.

Diretora do Mestrado Profissional em Administração - Gestão de Projetos - da Universidade Nove de Julho (PMPA-

GP/UNINOVE), Brasil.

cristinadm@uninove.br

http://lattes.cnpq.br/3471910853542167

\author{
Diego Maganhotto Coraiola - Editor Geral \\ Editor responsável pela submissão: \\ Washington José Souza. \\ Artigo analisado via processo de revisão duplo cego (Double-blind). \\ Recebido em: 20/12/2013 \\ Aprovado em: 25/06/2014 \\ Última Alteração: 2014/04/04
}

* Contato Principal: Francisco Matarazzo, 612 - Prédio C - 1o andar. Água Branca, São Paulo - SP, Brasil. CEP: 05001-100.. 


\section{PROCESSO DE SELEÇÃO DE PROJETOS NA GESTÃO DE PORTFÓLIO: O CASO DE UMA ORGANIZAÇÃO SEM FINS LUCRATIVOS}

\section{RESUMO}

As organizações sem fins lucrativos têm aumentado sua participação na sociedade e buscado, na área de conhecimento da administração, ferramentas que facilitam a direção, a liderança e o controle de suas rotinas de trabalho. O setor também apresenta adoção de técnicas de planejamento estratégico, tornando a aceitação da metodologia de gestão de portfólio de projetos uma consequência natural. Nesse cenário, o objetivo deste artigo é verificar as práticas desenvolvidas na seleção de projetos de uma Associação Médica Especializada à luz de modelos de gestão de portfólio de projetos. Por meio da realização de um estudo de caso exploratório como estratégia de pesquisa e técnica de avaliação qualitativa, conclui-se que a organização desenvolve um planejamento estratégico para a captação de recursos e aplica, parcial e informalmente, o processo de seleção de projetos para composição do portfólio. A análise à luz de quatro modelos, possibilitou identificar que não há um modelo aplicável ao caso estudado, mas que algumas fases dos mesmos são aderentes, sendo outras de difícil adequação ao contexto de organizações sem fins lucrativos. Por fim, a conclusão motiva reflexão e expectativa quanto à necessidade de se desenvolver metodologias aplicadas ao setor não lucrativo, que contemplem características e peculiaridades dessas organizações.

\section{Palavras-chave}

Gestão de Portfólio de Projetos, Organização sem fins lucrativos, Associação Médica.

\section{SELECTION PROCESS FOR PROJECTS IN PORTFOLIO MANAGEMENT: THE CASE OF A NONPROFIT ORGANIZATION}

\section{ABSTRACT}

Nonprofit organizations are increasing their participation in society and are also pursuing tools that facilitate the management leadership and control of their work routines, in the Administration area of knowledge. These organizations also present the adoption of strategic planning techniques, which happens to make the acceptance of the project portfolio management methodology a natural consequence. Based on this context, the goal of this paper is to verify a Specialized Medical Association's the practices developed in selecting projects, by using models of project portfolio management. Through an exploratory case study as a research strategy and qualitative evaluation technique, we conclude that the organization develops strategic planning for fundraising and partially and informally applies the process of selecting projects for portfolio composition. The analysis in the light of the four models, identified that there is a model applicable to the case studied, but some of these phases are adherent, and other hard to fit the context of nonprofit organizations. Finally, the conclusion motivates reflection and expectation on the need to develop methodologies applied to the nonprofit sector that contemplates the characteristics and peculiarities of these organizations.

\section{Keywords}

Project Portfolio Management, Nonprofit Organization, Medical Association. 


\section{Introdução}

No Brasil, assim como no exterior, as organizações da sociedade civil sem fins lucrativos têm aumentado cada vez mais sua participação na sociedade (Heckert \& Silva, 2008), e muito mais é exigido dessas entidades no nível de profissionalização e de gestão de projetos altamente qualificados (Mariano \& Rocha, 2011). Essas organizações também devem utilizar técnicas administrativas eficazes, pela necessidade de desenvolverem autossustentabilidade, a fim de desempenharem bem os seus papeis (Oliveira, Ross, \& Altimeyer, 2005).

A administração surge como área de conhecimento portadora de soluções para os problemas dessas instituições, por meio de temas que já se tornaram comuns entre o setor: planejamento, gestão de projetos, marketing, finanças, entre outros (Falconer, 1999). Segundo Silveira, Campos e Marcon (2006), muitas organizações sem fins lucrativos (OSFL) têm utilizado instrumentos que facilitam a direção, liderança, organização e controle de suas rotinas de trabalho. Todavia, mais do que adequações em termos de aplicabilidade, as ferramentas de gestão que contribuem para o sucesso das empresas "de mercado", quando utilizadas, devem ser adaptadas para uso das organizações sem fins lucrativos (Andion, 2005; Mariano \& Rocha, 2011; Oliveira et al., 2005).

A adoção de técnicas de planejamento estratégico tem tido aceitação entre as organizações sem fins lucrativos (Oliveira et al., 2005; Ruggeri, 2011). A gestão de portfólio é uma consequência natural em organizações desenvolvedoras de ações fortemente baseadas em projetos. Portanto, a aceitação de técnicas, ferramentas e metodologias de gestão de projetos alinhadas às necessidades da gestão estratégica e da gestão de portfólios é um passo inevitável desse desenvolvimento (Ruggeri, 2011).

Contudo, mesmo que na atualidade a literatura de projetos tenha explorado o tema gestão de portfólio (Rabechini, Maximiano, \& Martins, 2005), ainda são poucos os estudos sobre suas práticas no contexto das organizações (Castro \& Carvalho, 2010a; Castro \& Carvalho, 2010b; Rabechini et al., 2005), não havendo consenso entre os executivos sobre sua importância (Archer \& Ghasemzadeh, 1999; Cooper, Edgett, \& Kleinschmidt, 1999). Além disso, é identificada aparente lacuna referente à existência de uma metodologia estruturada para a definição de portfólio de projetos em organizações sem fins lucrativos (Rocha, Treinta, Coutinho, \& Farias, 2009; Ruggeri, 2011). Desse modo, este artigo busca contribuir, por meio de uma análise teórico-empírica, para o aprimoramento e desenvolvimento da gestão de portfólio de projetos, de modo especial no contexto de organizações sem fins lucrativos.

Diante desse cenário, e tendo em vista a relevância acadêmica, social e econômica dessa temática, a questão de pesquisa que norteia este estudo é a seguinte: qual a aplicabilidade dos modelos de gestão de portfólio de projetos na seleção de projetos de uma organização sem fins lucrativos? Assim, o principal objetivo deste trabalho é verificar as práticas desenvolvidas na seleção de projetos de uma Associação Médica Especializada à luz de modelos de gestão de portfólio de projetos.

O artigo é apresentado em seis seções, contando com esta introdução. A seção 2 apresenta aspectos conceituais sobre a gestão de portfólio de projetos e processos de gestão de portfólio, descrevendo quatro modelos mais recorrentes na literatura. Em seguida, a seção 3 explica os procedimentos metodológicos adotados. Na seção 4, a análise dos resultados do estudo é apresentada e, na seção 5 , os resultados são discutidos. Finalmente, a seção 6 traz as considerações finais.

\section{Referencial Teórico}

Nesta seção é feita uma abordagem dos aspectos conceituais pertinentes à gestão de portfólio de projetos e aos processos de gestão de portfólio, incluindo quatro modelos identificados na literatura e relevantes ao objetivo deste estudo.

\subsection{Gestão de Portfólio de Projetos}

A gestão de portfólio de projetos tem se mostrado um tema de destaque, assim como o portfólio de negócio nos anos 70 e 80 (PMI, 2012). Desde a década de 90, as áreas de conhecimento de gestão de projetos e gestão de portfólio começam, de fato, a unificarem-se, recebendo a denominação de gerenciamento de portfólio de projetos pelos estudiosos, ou simplesmente a sigla de PPM (Project Portfolio Management) (Castro \& Carvalho, 2010a).

No Brasil, um dos pioneiros na análise da aplicação das técnicas de portfólio na gestão de projetos foi o autor Kruglianskas (1992), considerando que os recursos da empresa são limitados e os projetos devem estar alinhados com os objetivos da mesma (Castro \& Carvalho, 2010b). Kerzner (2011) argumenta que a gestão de projetos é caracterizada por métodos de reestruturação da administração e adaptação de técnicas especiais de gestão. Para o autor, a finalidade de se adotar esse conhecimento é a busca por melhor controle e utilização dos recursos existentes.

Para Rabechini et al. (2005), além dos projetos e programas, uma nova forma de gestão tem se apresentado no mundo corporativo. Contudo tem sido pouco explorada pelas empresas brasileiras: a gestão de portfólio - gerenciamento centralizado de um ou mais portfólio composto por um conjunto de projetos e/ou 
programas e outros trabalhos de forma sistêmica para alcançar os objetivos estratégicos de negócios (PMI, 2012). Esse gerenciamento contribui para determinar a exata combinação de projetos com o correto nível de investimento, resultando em um maior equilíbrio entre projetos em andamento e novas iniciativas estratégicas (Kerzner, 2006).

A gestão de portfólio é um processo de decisão dinâmico que objetiva avaliar, selecionar e priorizar novos projetos (Cooper, Edgett, \& Kleinschmidt, 1999; Cooper et al., 2001), sendo vital para o desempenho e sucesso do negócio (Cooper et al., 1999), por meio de quatro metas principais (Cooper et al., 2001): a) alocar recursos para maximizar o valor do portfólio; b) desenvolver o balanceamento de projetos do portfólio; c) alcançar um portfólio estrategicamente alinhado, e; d) alcançar um número adequado de projetos para a quantidade de recursos limitados disponíveis.

Segundo Carneiro e Martens (2012), nas organizações que possuem objetivos estratégicos intimamente ligados à realização de projetos, a gestão de portfólio de projetos torna-se importante. Como um processo estratégico, a gestão de portfólio é orientada pela missão da organização, consequentemente, está relacionada à organização como um todo (Rad \& Levin, 2006).

É necessário que as organizações tenham todo um processo estratégico definido, estabelecendo por meio do planejamento estratégico, suas metas e objetivos estratégicos (PMI, 2008), devendo ser considerados fatores externos e internos do negócio, antecipadamente ao processo de montagem do portfólio de projetos (Archer \& Ghasemzadeh, 1999). Wheelwright and Clarck (1993 como citado em Rabechini et al., 2005, p. 424), recomendam o estabelecimento de prazos de até um ano para alocação de recursos de uma carteira de projetos de uma organização.

O planejamento estratégico torna-se uma importante ferramenta gerencial tanto para as organizações que objetivam o lucro como alvo, quanto para aquelas que não o almejam, uma vez que contribui para realizar a apropriada alocação dos recursos e fortalecer a organização financeiramente (Mara, 2000). A ideia de se elaborar estratégias explícitas tem se tornado comum nas OSFL, já que essas necessitam reagir às mudanças mais rápidas em seu ambiente externo, tendo necessidade em demonstrar aos financiadores o que será feito com o recurso aplicado (Hudson, 1999). Para Drucker (2012, p. 73) “a estratégia converte a missão e os objetivos da instituição sem fins lucrativos em desempenho".

Dessa forma, o alinhamento do portfólio de projetos à estratégia da organização assume importância especial nas OSFL (Ruggeri, 2011), uma vez que, se esse alinhamento não ocorrer, por vezes, essas organizações poderão estar desprezando recursos e, até mesmo, prejudicando o alcance das metas definidas (Rocha, Treinta, Coutinho, \& Farias, 2009).

\subsection{Processos de Gestão de Portfólio}

Para Antunes, Loos e Miguel (2012), o ciclo de processos de um portfólio pode ser definido como: planejamento, autorização e monitoramento, e controle, sendo executados de modo consecutivo, pelo gerenciamento executivo, gerenciamento de portfólio, gerenciamento de projetos e programas, e gerenciamento operacional. Esses autores enfatizam que é essencial para o sucesso da gestão de portfólio o apoio de todos os níveis de gerência, bem como a comunicação entre os mesmos.

As organizações têm iniciado diferentes projetos com múltiplas perspectivas de negócios e expectativas, com o intuito de alcançar metas de longo prazo para o negócio e outros com vistas a metas mais imediatas (Rad \& Levin, 2006). Desde características do próprio negócio até os contextos ambiental e cultural de cada organização devem ser considerados na escolha de um modelo para o gerenciamento do portfólio (PMI, 2008). $\mathrm{Na}$ visão de Archer and Ghasemzadeh (1999) essa complexidade, considerando que exista uma definição de metas estratégicas para a organização, faz com que o maior desafio de um modelo para a gestão de portfólio, talvez seja a seleção de projetos componentes desse portfólio.

Os autores Rabechini e Carvalho (2006), ilustram o processo de avaliação e seleção de projetos por meio de um "funil", no qual as ideias geradas são rigidamente selecionadas e encaminhadas às fases seguintes, de modo que o resultado final seja uma lista de projetos alinhados à estratégia do negócio, conforme representado pela Figura 1.

A existência de técnicas relativamente divergentes pode ser usada na estimativa, avaliação e escolha de projetos para um portfólio. Contudo, muitas dessas técnicas não são amplamente aplicadas devido a sua complexidade, exigência de muitos dados de entrada, ou, simplesmente, por apresentarem alto grau de dificuldade no entendimento e uso pelos tomadores de decisão (Archer \& Ghasemzadeh, 1999). Estudos realizados na América do Norte e na Europa mostram que os gestores apresentavam uma aversão, por exemplo, às técnicas matemáticas, devido à dificuldade de entender e aplicar (Cooper et al., 1999). 


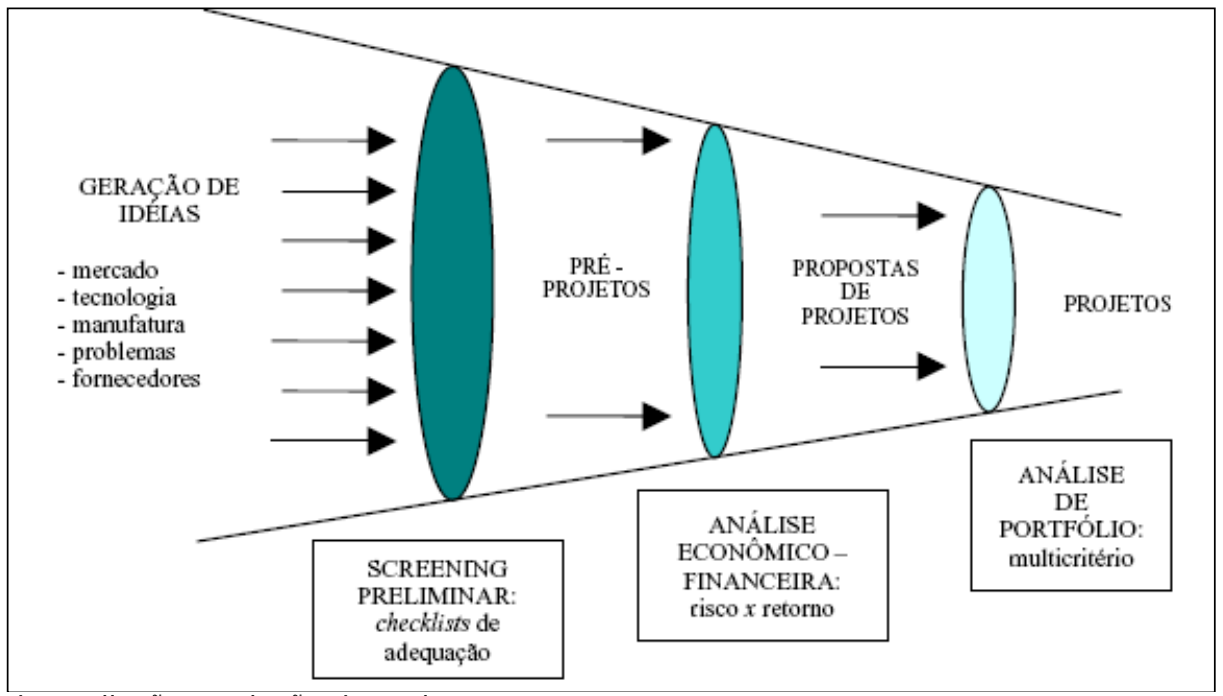

Figura 1. Processo de avaliação e seleção de projetos Fonte: Adaptado de Rabechini Jr. \& Carvalho (2006).

\begin{tabular}{|c|c|c|}
\hline Métodos & Vantagens & Desvantagens \\
\hline Financeiro & $\begin{array}{l}\text { Apesar de ser o mais popular, não existe } \\
\text { nenhuma vantagem evidente deste método. }\end{array}$ & $\begin{array}{l}\text { Apesar da sua popularidade, é o método } \\
\text { com maior número de desvantagens por: } \\
\text { não oferecer balanceamento, não } \\
\text { promover a utilização de janelas de } \\
\text { oportunidade de mercado, não ser } \\
\text { compreendido pelos gestores, não } \\
\text { considerar os elementos chave de tomada } \\
\text { de decisão, entre outros. }\end{array}$ \\
\hline $\begin{array}{l}\text { Abordagem } \\
\text { estratégica }\end{array}$ & $\begin{array}{l}\text { Método com melhor desempenho, } \\
\text { apresentando as seguintes vantagens: } \\
\text { alinhamento com a estratégia, projetos de alto } \\
\text { valor são selecionados, gastos refletem a } \\
\text { estratégia, o método se ajusta ao estilo de } \\
\text { decisão, é bem compreendido e fácil de utilizar. }\end{array}$ & $\begin{array}{l}\text { Este método não é bem utilizado na } \\
\text { análise individual de projetos nem permite } \\
\text { um bom balanceamento entre os mesmos. }\end{array}$ \\
\hline Pontuação & $\begin{array}{l}\text { Excelente no ajuste ao estilo de decisão e na } \\
\text { seleção de projetos de alto valor, e também } \\
\text { apresenta bons resultados no alinhamento à } \\
\text { estratégia. }\end{array}$ & $\begin{array}{l}\text { Não é fácil de utilizar e não restringe a } \\
\text { quantidade à capacidade da organização. }\end{array}$ \\
\hline $\begin{array}{l}\text { Diagrama } \\
\text { de bolhas }\end{array}$ & $\begin{array}{l}\text { Apesar da pouca utilização mostra bom } \\
\text { alinhamento estratégico, efetividade, facilidade } \\
\text { na utilização e permite selecionar projetos de } \\
\text { alto valor. }\end{array}$ & $\begin{array}{l}\text { Não restringe a quantidade à capacidade } \\
\text { da organização, apresenta lentidão e os } \\
\text { gastos não refletem a estratégia. }\end{array}$ \\
\hline
\end{tabular}

Figura 2. Métodos de avaliação de projetos

Fonte: Adaptado de Castro, H. G. de, \& Carvalho, M. M. de. (2010b). Gerenciamento do portfólio de projetos (PPM): estudos de caso. Produção, 20(3), 303-321.

O estudo realizado por Cooper et al. (1999) envolvendo 205 empresas de pesquisa e desenvolvimento de produtos concluiu que não há monopólio de nenhum método de gestão de portfólio e que são utilizados mais de um método ou técnicas. Em ordem de classificação de popularidade os métodos são: financeiros - 77,3\%; estratégia de negócios - 64,8\%; diagrama de bolhas - 40,6\%; pontuação - 37,9\%; e, listas - 20,9\%. O resultado percentual de $241,5 \%$ sugere que as empresas utilizam mais de um método, isto é, cerca de 2,4 tipos de métodos de gestão de portfólio de projetos.

Contudo, ainda são incipientes estudos relacionados à gestão de portfólio em OSFL. Corrobora-se com Ruggeri (2011) ao afirmar que, aparentemente, a construção de portfólio de projetos nessas organizações não possui nenhuma metodologia estruturada. Para esse autor, isso é resultado de um desenvolvimento ainda embrionário da utilização de métodos de planejamento estratégicos mais estruturados, uma vez que, teoricamente, deve preceder à gestão de portfólio de projetos.

Para a seleção de projetos nas OSFL é necessário selecionar e adequar os métodos e critérios a serem utilizados. Essas organizações tendem a utilizar métodos não numéricos, ainda que alguns métodos numéricos sejam possíveis. Justifica-se que a preferência por métodos não numéricos é devido à dificuldade de se traduzir certos resultados em termos monetários para a realidade não lucrativa. Ao mesmo tempo, os métodos não numéricos contribuem para o aumento de participantes nos grupos de decisão, sendo muito atrativo para o setor (Ruggeri, 2011). A Figura 3 resume os principais aspectos dos métodos que deverão ser levados em consideração para a seleção de projetos de acordo com Ruggeri (2011) e Rodrigues (2010). 


\begin{tabular}{|c|c|c|}
\hline Método & Consideração & Autor \\
\hline \multirow{5}{*}{$\begin{array}{l}\text { Numérico } \\
\text { (Financeiro/ } \\
\text { Econômico) }\end{array}$} & $\begin{array}{l}\text { Taxas de atualização, previsões de receitas futuras e estimativas de despesas } \\
\text { são valores estabelecidos em dados com maior ou menor confiabilidade. }\end{array}$ & \multirow{2}{*}{$\begin{array}{l}\text { Ruggeri } \\
(2011)\end{array}$} \\
\hline & Dificuldade de traduzir certos resultados em termos monetários. & \\
\hline & $\begin{array}{l}\text { Não há como garantir que os parâmetros utilizados na comparação dos } \\
\text { resultados serão igualmente característicos antes e depois do projeto. }\end{array}$ & \multirow{3}{*}{$\begin{array}{l}\text { Rodrigues } \\
(2010) \text {. }\end{array}$} \\
\hline & $\begin{array}{l}\text { E muito difícil estabelecer até quando e com que ponderação os resultados de } \\
\text { uma intervenção terão efeito. }\end{array}$ & \\
\hline & $\begin{array}{l}\text { A taxa de desconto não é aplicável. Como o tipo de parâmetro utilizado para } \\
\text { avaliar os resultados não é financeiramente mensurável de forma objetiva, } \\
\text { sempre haverá dúvida sobre a interferência da taxa considerada sobre ele. }\end{array}$ & \\
\hline \multirow{2}{*}{$\begin{array}{l}\text { Não } \\
\text { numérico }\end{array}$} & $\begin{array}{l}\text { Necessidade operacional/competitiva, expansão/adequação à linha de } \\
\text { produtos, comparação de benefícios, são passíveis de uso com algumas } \\
\text { adaptações. }\end{array}$ & \multirow{2}{*}{$\begin{array}{l}\text { Ruggeri } \\
(2011) \text {. }\end{array}$} \\
\hline & $\begin{array}{l}\text { Facilita a participação de grupos maiores nas decisões, sendo atrativo para o } \\
\text { setor. }\end{array}$ & \\
\hline \multirow{2}{*}{ Pontuação } & $\begin{array}{l}\text { São úteis porque permitem a inclusão, num mesmo modelo de seleção, de } \\
\text { diversos aspectos da decisão - não financeiros. }\end{array}$ & \multirow{2}{*}{$\begin{array}{l}\text { Ruggeri } \\
(2011)\end{array}$} \\
\hline & $\begin{array}{l}\text { Os modelos devem adequar-se às possibilidades técnicas de análise da } \\
\text { organização. }\end{array}$ & \\
\hline
\end{tabular}

Figura 3. Métodos para seleção de projetos no contexto não lucrativo

Fonte: Elaborado pelos autores.

Com base nos levantamentos da literatura, na Figura 4 é apresentada uma análise comparativa entre os modelos de gestão de portfólio de projetos mais recorrentes, os quais são abordados na sequência.

\begin{tabular}{|c|c|c|c|c|c|c|c|}
\hline Modelo & Estratégia & Identificação & Categorização & Seleção & Priorização & Balanceamento & Controle \\
\hline $\begin{array}{c}\text { Archer and } \\
\text { Ghasemzadeh } \\
(1999) .\end{array}$ & $\begin{array}{c}\text { Pré- } \\
\text { condição }\end{array}$ & Explícito & Implícito & Explícito & Implícito & Explícito & Implícito \\
\hline $\begin{array}{c}\text { Rabechini et } \\
\text { al. (2005). }\end{array}$ & $\begin{array}{c}\text { Pré- } \\
\text { condição }\end{array}$ & Explícito & Implícito & Explícito & Implícito & Explícito & Explícito \\
\hline PMI (2008). & $\begin{array}{c}\text { Pré- } \\
\text { condição }\end{array}$ & Explícito & Explícito & Explícito & Explícito & Explícito & Explícito \\
\hline $\begin{array}{c}\text { Rocha, } \\
\text { Treinta, } \\
\text { Coutinho e } \\
\text { Farias (2009). }\end{array}$ & Explícito & Explícito & Implícito & Explícito & Explícito & Explícito & Implícito \\
\hline
\end{tabular}

Figura 4. Modelos e atividades na gestão de portfólio de projetos

Fonte: Elaborado pelos autores baseado em Rocha, M. H. P. da, \& Negreiros, L. A. de. (2009). Alinhamento estratégico e o gerenciamento de portfólio de projetos nas organizações. V Congresso Nacional de Excelência em Gestão (pp. 1-18). Rio de Janeiro.

\subsubsection{O modelo de Archer \& Ghasemzadeh}

Esse modelo, desenvolvido na década de 90 e destacado como referência na área de gestão de portfólio de projetos (Castro \& Carvalho, 2010b), objetiva a simplificação do processo de seleção de projetos (Archer \& Ghasemzadeh, 1999). Esses autores propõem um modelo de PPM (Project Portfolio Management) a partir da segmentação do processo em fases e estágios, desde as considerações relativas à estratégia inicial - modo mais amplo - até a elaboração final do portfólio. Todavia, “os usuários têm liberdade para escolher as técnicas mais adequadas para cada fase ou, em alguns casos, omitir ou modificar uma fase, se isso for simplificar e agilizar o processo" (Archer \& Ghasemzadeh, 1999, p. 207).

\begin{tabular}{|c|c|c|c|}
\hline $\begin{array}{l}\text { Fase do } \\
\text { Processo }\end{array}$ & Estágio de Seleção & Atividades & Metodologias potenciais \\
\hline Pré-Processo & $\begin{array}{l}\text { Desenvolvimento do } \\
\text { foco estratégico }\end{array}$ & $\begin{array}{l}\text { Mapa estratégico, matriz de } \\
\text { portfólio. }\end{array}$ & $\begin{array}{l}\text { Definidas na estratégia da } \\
\text { organização. }\end{array}$ \\
\hline \multirow{5}{*}{$\begin{array}{l}\text { Processo de } \\
\text { Seleção do } \\
\text { Portfólio }\end{array}$} & $\begin{array}{l}\text { Seleção inicial dos } \\
\text { projetos }\end{array}$ & $\begin{array}{l}\text { Rejeição de projetos que não } \\
\text { atendam aos critérios definidos. }\end{array}$ & $\begin{array}{l}\text { Estudos de viabilidade, } \\
\text { critérios e foco estratégico. }\end{array}$ \\
\hline & $\begin{array}{l}\text { Análise individual dos } \\
\text { projetos }\end{array}$ & $\begin{array}{l}\text { Cálculo dos parâmetros comuns } \\
\text { dos projetos. }\end{array}$ & Árvore de decisão, ROI, VPL. \\
\hline & Seleção dos projetos & Rejeição de projetos inviáveis. & Técnicas ad hoc. \\
\hline & Definição do portfólio & $\begin{array}{l}\text { Verificação de interações, } \\
\text { análise dos atributos do projeto } \\
\text { e restrições de recursos. }\end{array}$ & $\begin{array}{l}\text { Scoring models, AHP, } \\
\text { análise de sensibilidade. }\end{array}$ \\
\hline & Ajuste do portfólio & $\begin{array}{l}\text { Ajustes direcionados aos } \\
\text { usuários. }\end{array}$ & $\begin{array}{l}\text { Matriz e análise de } \\
\text { sensibilidade. }\end{array}$ \\
\hline Pós-Processo & $\begin{array}{l}\text { Finalização do } \\
\text { portfólio }\end{array}$ & Desenvolvimento dos projetos. & $\begin{array}{l}\text { Técnicas de gestão de } \\
\text { projetos, coleta de dados. }\end{array}$ \\
\hline
\end{tabular}

Figura 5. Atividades e metodologias na seleção de portfólio de projetos

Fonte: Adaptado de Archer, N. P., \& Ghasemzadeh, F. (1999). An integrated framework for project portfolio selection. International Journal of Project Management, 17(4), 207-216. 
O modelo de Archer and Ghasemzadeh (1999) é apresentado em três fases: pré-processo, processo de seleção (subdividido em fases) e pós-processo. Na Figura 5 são apresentadas as características de cada fase, bem como as metodologias ou ferramentas que permitem sua realização, possibilitando alcançar a máxima cooperação dos tomadores de decisão durante o processo de seleção do portfólio.

Segundo Archer and Ghasemzadeh (1999), a seleção de metodologia e o desenvolvimento de estratégia só precisam ser revistos conforme necessidade, e não sempre que o portfólio for reavaliado. Também, na fase de seleção do portfólio, o processo de otimização pode ser simplificado, dependendo das circunstâncias.

\subsubsection{O modelo de Rabechini, Maximiano \& Martins}

O modelo desenvolvido por Rabechini et al. (2005), que utilizou como base, dentre outros modelos, o de Archer and Ghasemzadeh (1999), foi aplicado em uma empresa brasileira prestadora de serviços de interconexão eletrônica (Castro \& Carvalho, 2010b). Esse modelo, segundo Rabechini et al. (2005), constituído com base nas experiências acadêmicas e práticas em organizações, propõem seis dimensões com as respectivas características e finalidades para o gerenciamento de portfólio de projetos, sendo:

1. Preparação do processo de implementação da gestão de portfólio: deve ser delineado um contexto estratégico de modo a permitir a exploração do planejamento estratégico da organização, incluindo, também, uma análise do ambiente (interno e externo). Destaca-se a necessidade de amplo conhecimento pelos interessados dos modelos de negócios, dos elementos estratégicos e da metodologia de avaliação de projetos, para poder enquadrar os projetos e avaliá-los corretamente. Essa dimensão deve contemplar critérios ponderados para a avaliação das iniciativas candidatas ao portfólio, ou seja, identificação dos critérios e o estabelecimento dos respectivos pesos.

2. Identificação de projetos: com o intuito de estruturar o portfólio de projetos essa dimensão visa que cada área da organização deverá apresentar por meio de um documento, as devidas justificativas sobre os projetos, com informações mínimas de objetivos, prazo, risco, custo e indicadores de sucesso capazes de fundamentar sua execução. A principal saída dessa dimensão será uma lista completa de projetos.

3. Avaliação: busca estabelecer uma lista priorizada de projetos, devendo ser agregadas informações relevantes e notas em função dos critérios determinados na primeira dimensão.

4. Constituição da carteira: visa constituir um plano de gestão do portfólio que contemple, inclusive, a elaboração de regras para a inserção de novos projetos, visto que esses passarão a competir por recursos da organização.

5. Administração: essa dimensão constitui-se no gerenciamento do portfólio baseado nos elementos de controle dos recursos alocados nos projetos, no acompanhamento do ciclo de vida dos projetos, nos custos e cronogramas definidos dos projetos, na qualidade, bem como nas competências de recursos humanos necessárias para o sucesso e desempenho do portfólio.

6. Revisão e controle: segundo a metodologia de gestão de projetos adotada pela organização, essa dimensão consiste na definição e verificação dos indicadores de andamento do projeto, seu alinhamento estratégico, bem como da tomada de decisão para as eventuais mudanças no portfólio de projetos.

Rabechini et al. (2005) iniciaram a aplicação do modelo com um levantamento das informações estratégicas e definiram os limites da organização a ser analisada, envolvendo os administradores. Os autores destacam que um importante ponto referente ao processo de seleção de projetos está relacionado à dificuldade na utilização de um sistema de ponderação por critérios - objetivos e subjetivos - que, por vezes, não são capazes de corresponder aos anseios absolutos dos tomadores de decisão, a exemplo de fatores de ordem política ou pessoal.

\subsubsection{O modelo padrão de gerenciamento de portfólio do PMI}

Em 2006, o Project Management Institute (PMI), instituição que tem se destacado pela penetração nas organizações brasileiras (Castro \& Carvalho, 2010b), lançou seu padrão de gerenciamento de portfólio - The Standard for Portfolio Management. A segunda versão, apresentada em 2008, traz a descrição do conhecimento e das práticas de gestão de portfólio aplicáveis com utilidade (PMI, 2008). Contudo, isso não significa que os processos descritos pelo PMI sejam sempre válidos, tendo sua aplicação generalizada em todos os casos de gestão de portfólio. Para o PMI (2008), a proposta do The Standard for Portfolio Management é que esse seja utilizado como uma referência e base para o desenvolvimento de metodologias favoráveis ao contexto de cada organização.

O modelo padrão de gerenciamento de portfólio do PMI é estabelecido por processos apresentados pelo agrupamento por similaridade de função, sendo ainda divididos em áreas de conhecimento. A gestão de portfólio é dividida em dois grupos: (i) alinhamento estratégico - objetiva garantir a disponibilidade de subsídios relacionados aos objetivos estratégicos que o portfólio deve apoiar, e; (ii) monitoramento e controle - busca avaliar se o portfólio está contribuindo para o alcance dos objetivos estratégicos da organização (PMI, 2008). 


\begin{tabular}{|c|c|c|}
\hline Processo & Objetivo & Atividade \\
\hline Identificação & $\begin{array}{l}\text { Criar uma lista atualizada com as } \\
\text { informações necessárias para que } \\
\text { se faça a escolha dos componentes } \\
\text { para o portfólio. }\end{array}$ & $\begin{array}{l}\text { Comparar componentes ativos com novas } \\
\text { propostas utilizando definições predeterminadas; } \\
\text { rejeitar os componentes que não se enquadrarem } \\
\text { às definições predeterminadas, e; classificar } \\
\text { componentes identificados dentro de classes } \\
\text { predefinidas - projeto, programa, portfólio e outros } \\
\text { trabalhos. }\end{array}$ \\
\hline Categorização & $\begin{array}{l}\text { Agrupar os projetos em categorias } \\
\text { de acordo com a relevância para o } \\
\text { negócio, a fim de que filtros ou } \\
\text { critérios possam ser aplicados para } \\
\text { avaliação, seleção, priorização e } \\
\text { balanceamento do portfólio. }\end{array}$ & $\begin{array}{l}\text { Identificar categorias estratégicas baseadas no } \\
\text { planejamento estratégico; comparar os } \\
\text { componentes identificados com as categorias, e; } \\
\text { agrupar cada componente dentro de uma das } \\
\text { categorias. }\end{array}$ \\
\hline Avaliação & $\begin{array}{l}\text { Comparar os projetos tendo como } \\
\text { base as informações disponíveis, a } \\
\text { fim de que seja possível sua } \\
\text { avaliação. }\end{array}$ & $\begin{array}{l}\text { Avaliar os projetos utilizando critérios-chave por } \\
\text { meio de um modelo de comparações por pesos - } \\
\text { scoring model. }\end{array}$ \\
\hline Seleção & $\begin{array}{l}\text { Fornecer uma lista resumida de } \\
\text { projetos, baseado na avaliação e } \\
\text { recomendações dos critérios de } \\
\text { seleção definidos pela organização. }\end{array}$ & $\begin{array}{l}\text { Produzir uma lista de projetos; determinar o valor } \\
\text { de cada projeto, e; adequar as informações } \\
\text { necessárias para a priorização e balanceamento do } \\
\text { portfólio. }\end{array}$ \\
\hline Priorização & $\begin{array}{l}\text { Ordenar os projetos em cada } \\
\text { categoria estratégica ou financeira e } \\
\text { foco organizacional estabelecido. }\end{array}$ & $\begin{array}{l}\text { Classificar os projetos permitindo análises } \\
\text { posteriores e necessárias para validação e } \\
\text { balanceamento do portfólio. }\end{array}$ \\
\hline Balanc & $\begin{array}{l}\text { Desenvolver um conjunto de } \\
\text { projetos de portfólio proporcionando } \\
\text { um maior suporte ao planejamento } \\
\text { e objetivos estratégicos da } \\
\text { organização. }\end{array}$ & $\begin{array}{l}\text { Revisar projetos existentes; excluir ou adicionar } \\
\text { novos projetos ao portfólio; planejar e alocar } \\
\text { recursos de modo que os riscos sejam minimizados } \\
\text { e a alocação de recursos da organização seja } \\
\text { maximizada. }\end{array}$ \\
\hline Autorização & $\begin{array}{l}\text { Alocar, formalmente, recursos } \\
\text { materiais, humanos e financeiros } \\
\text { para o início da execução dos } \\
\text { projetos selecionados, bem como } \\
\text { comunicar, convencionalmente, as } \\
\text { decisões de autorizar ou não um } \\
\text { projeto. }\end{array}$ & $\begin{array}{l}\text { Comunicar as decisões aos stakeholders; autorizar } \\
\text { a inclusão, retirada ou cancelamento de projetos } \\
\text { selecionados; realocar recursos humanos e } \\
\text { financeiros dos projetos excluídos; alocar } \\
\text { orçamentos e recursos para projetos incluídos, e; } \\
\text { comunicar, para cada projeto autorizado, quais são } \\
\text { as expectativas de resultados. }\end{array}$ \\
\hline
\end{tabular}

Figura 6. Grupo de processos de alinhamento estratégico

Fonte: Elaborado pelos autores com base no PMI, Project Management Institute (2008). The Standard for Portfolio Management (2nd ed., p. 146). Newton Square.

O grupo de alinhamento estratégico possui os seguintes processos: identificação, categorização, avaliação, seleção, priorização, balanceamento e autorização. Na Figura 6 são apresentados, sinteticamente, os objetivos e as atividades relevantes para cada um dos processos considerados pelo PMI (2008).

Composto pelos processos de revisão e relatório, e mudança estratégica, o grupo de monitoramento e controle é descrito, resumidamente, na Figura 7, relacionando seus objetivos e atividades (PMI, 2008).

O padrão de gerenciamento de portfólio do PMI também divide os processos em duas áreas de conhecimento: governança do portfólio e de gerenciamento de riscos. A área de governança do portfólio inclui os processos para a seleção e investimento no portfólio, o monitoramento e controle sobre os investimentos realizados, a comunicação de decisões relacionadas a esses investimentos, bem como a segurança de que os mesmos permaneçam alinhados aos objetivos estratégicos (PMI, 2008).

\begin{tabular}{|c|l|l|}
\hline Processo & \multicolumn{1}{|c|}{ Objetivo } & \multicolumn{1}{c|}{ Atividade } \\
\hline $\begin{array}{c}\text { Revisão e } \\
\text { relatório }\end{array}$ & $\begin{array}{l}\text { Reunir indicadores de } \\
\text { desempenho dos projetos e e } \\
\text { gerar relatórios dos } \\
\text { mesmos. }\end{array}$ & $\begin{array}{l}\text { Revisar, periodicamente, o portfólio para garantir alinhamento } \\
\text { dos projetos com a estratégia organizacional, bem como o de } \\
\text { recursos de modo eficiente. }\end{array}$ \\
\hline $\begin{array}{c}\text { Mudança } \\
\text { estratégica }\end{array}$ & $\begin{array}{l}\text { Prover o processo de } \\
\text { flexibilidade para adaptação } \\
\text { do portfólio as modificações } \\
\text { estratégicas da organização. }\end{array}$ & $\begin{array}{l}\text { Fornecer ferramentas e técnicas necessárias de modo a } \\
\text { determinar as ações que deverão ser tomadas quando as } \\
\text { modificações estratégicas ocorrerem. }\end{array}$ \\
\hline
\end{tabular}

Figura 7. Grupo de processos de monitoramento e controle

Fonte: Elaborado pelos autores com base no PMI, Project Management Institute (2008). The Standard for Portfolio Management (2nd ed., p. 146). Newton Square.

O gerenciamento de riscos é a área de conhecimento que está relacionada à apreciação de condições ou eventos que, uma vez ocorridos, possam ocasionar efeitos positivos ou negativos ao menos num objetivo estratégico do portfólio. Assim, a gestão de riscos no portfólio de projetos de uma organização, objetiva maximizar a probabilidade ou o impacto de eventos positivos e minimizar esses mesmos fatores, uma vez que possam influenciar negativamente o portfólio (PMI, 2008). 


\subsubsection{O Modelo de Rocha, Treinta, Coutinho \& Farias}

O modelo de Rocha et al. (2009) foi o único identificado na revisão da literatura direcionado, especificamente, ao terceiro setor. Nominado de GPORT, apresenta três partes principais cada qual em um nível organizacional diferente, permitindo múltiplas visões e conhecimentos da organização. Estabelece a figura de um administrador responsável pelo gerenciamento do processo e por garantir que as funções determinadas a cada envolvido sejam cumpridas. Segundo Rocha et al. (2009), o modelo também é composto por três grupos de avaliação (gerência de projetos, comitê científico e conselho executivo), com seus respectivos objetivos e atividades, além de serem classificados em três portais de avaliação nos níveis operacional, tático e estratégico, utilizando critérios pré-definidos conforme descritos a seguir:

1. Gerência de Projetos: responsável por acrescentar ao processo conhecimentos específicos da rotina dos projetos, sendo que sua principal atividade é a realização de pré-avaliações das propostas de projetos. Esse grupo é classificado como nível operacional. Critérios: abrangência, orçamento, capacidade de conclusão, risco, replicabilidade, sustentabilidade, localização, alinhamento aos objetivos do programa.

2. Comitê Técnico: responsável por adicionar conhecimentos técnicos relacionados aos projetos, que devem estar alinhados ao terceiro setor, sendo classificado no nível tático. Critérios: urgência, gravidade, viabilidade técnica, alinhamento ao terceiro setor.

3. Conselho Executivo: sua função é a de garantir que os projetos selecionados estejam aderentes com as estratégias da organização doadora, por isso, é classificado como nível estratégico. Critérios: viabilidade estratégica, visibilidade (imagem), alinhamento estratégico.

Uma ferramenta de apoio à tomada de decisão foi desenvolvida pelos autores Rocha et al. (2009) com o objetivo de facilitar a aplicação do modelo. Por meio dessa ferramenta, os autores buscam aumentar a aplicabilidade do modelo, garantir que o mesmo seja seguido na íntegra, de modo transparente, reunindo informações essenciais para que sejam utilizadas quando necessário. Um administrador é responsável pela ferramenta, devendo o mesmo ter conhecimento de todo o processo de gestão de portfólio, dos projetos candidatos e bom relacionamento com grupos pertencentes a cada portal (Rocha et al., 2009).

Destaca-se que o modelo GPORT não utiliza na análise dos projetos nenhum indicador financeiro (ROI, VPL), considera avaliação orçamentária e, exigindo a análise de especialistas em diversos níveis, pressupõe uma organização com capacidade de mobilizar tais análises.

Embora represente um avanço na gestão de portfólios em organizações do terceiro setor, um estudo mais analítico do GPORT, evidencia que sua arquitetura está direcionada para empresas financiadoras de projetos no terceiro setor e não, essencialmente, às organizações executoras destas ações (Ruggeri, 2011).

\section{Metodologia}

A presente pesquisa possui abordagem exploratória, pois buscou definir o problema com maior precisão e identificar sentidos relevantes de ação na obtenção de dados adicionais antes de poder desenvolver uma abordagem (Malhotra, 2006). Adotou-se a técnica de avaliação qualitativa com a finalidade de caracterizar a descrição, compreensão e interpretação de fatos e fenômenos (Martins \& Theóphilo, 2009). Nesse sentido, este estudo procura verificar as práticas desenvolvidas na seleção de projetos de uma Associação Médica Especializada à luz de quatro modelos de gestão de portfólio de projetos.

Fundada em 1941, a Associação Médica Especializada (AME), nome adotado neste estudo para fins de anonimato, é uma associação científica e cultural de médicos especialistas, de natureza privada sem finalidade lucrativa, é reconhecida como entidade de Utilidade Pública Federal. Sendo a principal entidade representativa da especialidade no Brasil, desenvolve suas atividades no setor de serviços implementando projetos de caráter social, científico, educativo e institucional, por meio de parcerias públicas e privadas.

A definição do campo da pesquisa foi motivada pelo fato da AME se destacar de outras OSFL ao realizar importantes projetos de saúde pública nacionais em parceria com o Ministério da Saúde, o Ministério da Educação e outras entidades médicas. Também por estar desenvolvendo novas ações estratégicas e sistemas de gestão, objetivando aumentar sua receita de patrocínios, um melhor planejamento e execução de seus projetos, a normatização de produtos e serviços para que a qualidade e o desempenho de suas atividades sejam, permanentemente, melhorados.

Por se tratar de uma investigação empírica de um fenômeno contemporâneo, adotou-se o estudo de caso como estratégia de pesquisa (Yin, 2010). A AME possui duas linhas de realização de projetos, sendo aquela que necessita de recursos privados captados junto aos fabricantes de produtos médicos, e a decorrente de parceria pública por meio de convênios. Para realização deste estudo, optou-se pelo portfólio de projetos da Associação que busca alcançar e manter parcerias privadas para a captação de recursos financeiros (patrocínios), planejados anualmente. Os projetos pela parceria pública surgem de necessidades pontuais da Associação e dos órgãos governamentais e, por isso, não foram considerados na análise.

A coleta de dados foi concretizada por meio da análise de documentos e registros em arquivos, 
envolvendo, ainda, a observação participante. Realizou-se, também, uma entrevista semiestrutura (Martins \& Theóphilo, 2009) com o responsável pela gestão de projetos na AME, que atua nessa atividade há mais de seis anos. Desse modo, a coleta de dados convergindo de maneira triangular, representa uma estratégia de análise, além de ser considerada um fator importante no estudo de caso utilizando diferentes fontes de evidências (Yin, 2010).

Para a realização da análise dos dados qualitativos, primeiramente realizou-se a redução de dados, a apresentação de dados e, o delineamento e busca das conclusões (Martins \& Theóphilo, 2009). Em seguida, conforme sugerido por Yin (2010), para a concretização da análise dos dados, adotou-se a estratégia geral de descrição do caso, que auxilia no desenvolvimento de uma estrutura analítica descritiva para organizar o estudo de caso.

\section{Caracterização da Organização e Análise do Processo de Gestão de Portfólio de Projetos}

Esta seção busca caracterizar a organização e apresentar os resultados da análise do processo de gestão de portfólio de projetos.

A organização foco de análise deste estudo, com sede na cidade de São Paulo, é dirigida por uma diretoria executiva composta por cinco médicos eleitos por escrutínio secreto para mandato de dois anos, tendo suas atribuições determinadas no Estatuto Social e descritas no Regimento Interno da organização. Possuem 19 colaboradores que são devidamente remunerados para desempenhar atividades administrativas, financeiras, assessoras e gerenciais, objetivando a prestação de serviços a cerca de 16.000 médicos associados em todo o território nacional. A Figura 8 representa o organograma da organização.

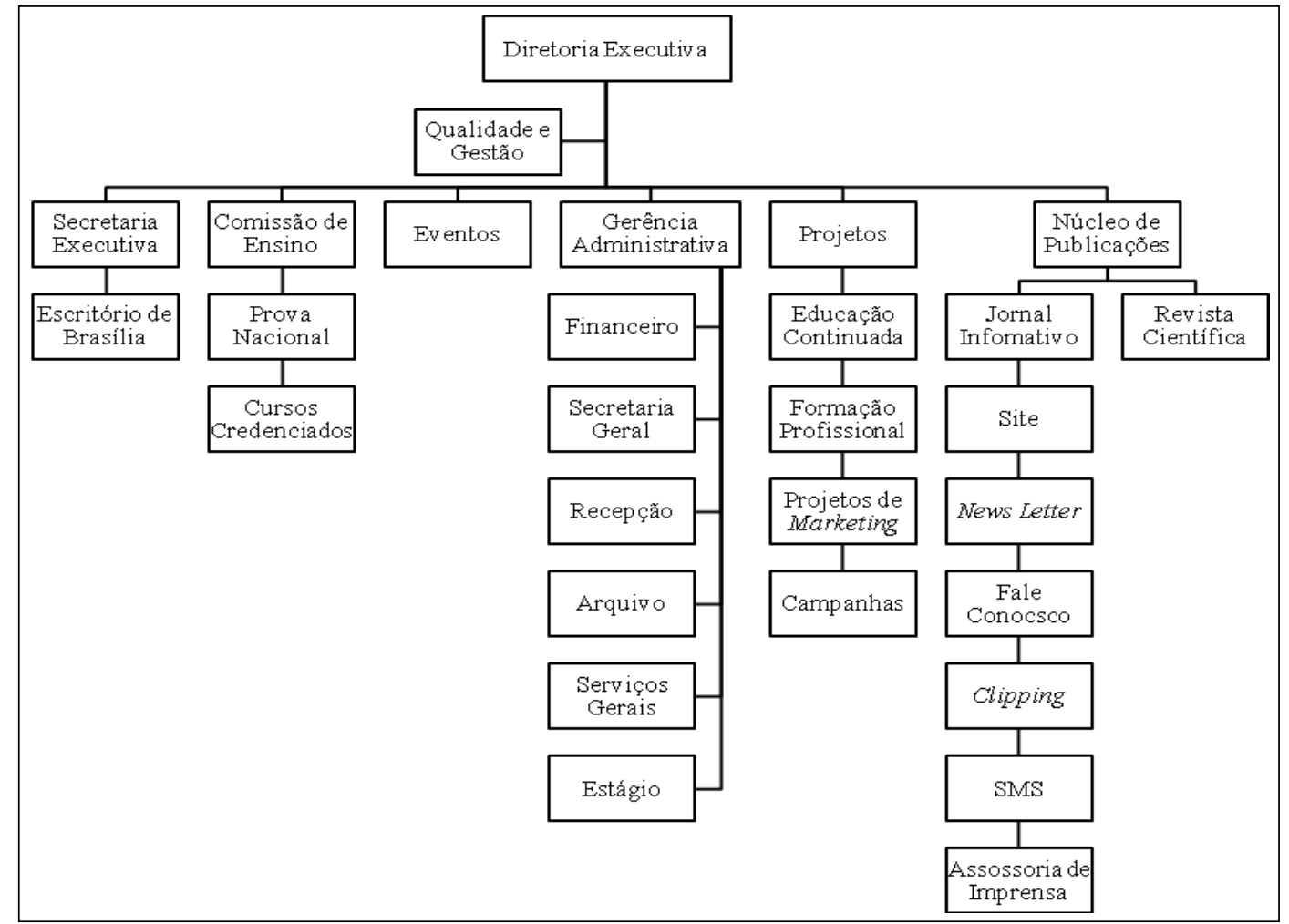

Figura 8. Organograma da Associação Médica Especializada

Fonte: Adaptado de documento do Sistema de Gestão da Qualidade.

Desde 2007, a AME tem apresentado seu plano anual de gestão por meio de projetos e propostas de parcerias com as empresas do setor (indústria farmacêutica e de produtos médicos), com o intuito de estabelecer o aporte de recursos financeiros necessários para investimento nas suas iniciativas educacionais, no aumento dos benefícios concedidos aos associados, no aprimoramento da comunicação com a classe médica e com a própria sociedade.

A partir de 2008, empresas farmacêuticas e de produtos médicos de capital nacional e internacional, passaram a patrocinar todos os projetos planejados anualmente pela organização, sendo criado o Grupo de Parceiros Especiais (GPE). Caracterizada como uma ação estratégica da organização, a criação do GPE é decorrente da dificuldade na captação de patrocínio, já que a concorrência com outras entidades tem sido cada vez mais acirrada, e pela própria exigência dos patrocinadores de melhor planejamento e viabilidade econômica dos projetos propostos, bem como dos retornos do investimento.

O portfólio de projetos tem sido planejado nos últimos cinco anos entre os meses de outubro e novembro, 
sendo apresentado e negociado com as empresas que fazem parte do GPE entre novembro e dezembro, para realização no exercício seguinte. A única restrição para a aceitação de uma empresa no GPE é que ela deve patrocinar todos os projetos que compõe o portfólio, não sendo permitida a escolha de projetos individuais.

A parceria é formalizada por meio de contrato anual que, além de prever cláusulas legais, descreve, resumidamente, a finalidade do projeto, suas características, o público alvo, a previsão de realização, o valor do patrocínio, a forma de pagamento e o respectivo benefício destinado à empresa patrocinadora, podendo ser por meio da veiculação de anúncios comerciais e institucionais, da logomarca, de depoimentos, de texto de agradecimento, dentre outros.

A Tabela 1 demonstra a evolução no portfólio de projetos realizados e de recursos financeiros captados (patrocínios) no período de 2008 a 2012. Com relação ao ano de 2013, é apresentado apenas o número de projetos planejados devido às negociações não terem sido finalizadas no momento de realização deste estudo.

Tabela 1

Portfólio de projetos realizados e recursos financeiros captados

\begin{tabular}{c|c|c|c}
\hline Ano & Projetos & GPE & Patrocínios \\
\hline 2008 & 8 & 5 & $\mathrm{R} \$ 1.173 .439,00$ \\
\hline 2009 & 9 & 5 & $\mathrm{R} \$ 318.000,00$ \\
\hline 2010 & 9 & 7 & $\mathrm{R} \$ 1.089 .035,00$ \\
\hline 2011 & 11 & 6 & $\mathrm{R} \$ 1.008 .810,00$ \\
\hline 2012 & 21 & 7 & $\mathrm{R} \$ 1.006 .251,50$ \\
\hline 2013 & 20 & Em negociação & $\mathrm{Em}$ negociação \\
\hline
\end{tabular}

Fonte: Dados coletados no início de 2013. Elaborado pelos autores.

A análise da Tabela 1 revela um crescimento no número de projetos, uma variação no número de empresas participantes do GPE, com o volume de receitas estáveis. Devido ao atraso na elaboração dos contratos e na realização dos projetos em 2008, o ano de 2009 foi planejado apenas para o segundo semestre, o que justifica a redução no valor dos recursos, mesmo que o número de projetos tenha sido mantido.

Mesmo diante de um aparente planejamento estratégico eficaz, e tendo considerado o departamento de projetos em seu organograma, a organização não adota uma metodologia formal e estruturada para a definição das estratégias e composição do seu portfólio de projetos. Pode-se dizer que, mesmo sem critérios formais préestabelecidos, há uma dinâmica de análise de propostas de novos projetos e de avaliação do desempenho obtido com os projetos do ano anterior, para que os mesmos sejam incluídos no portfólio do ano seguinte. No entanto, essa metodologia pode ser completamente alterada com o início de uma nova gestão, ou seja, a eleição de uma nova diretoria executiva.

O departamento de projetos é o responsável pelo processo de planejamento estratégico e de todas as informações necessárias para a definição do portfólio, bem como da execução e desenvolvimento dos projetos, mas não possui autonomia para a tomada de decisão. Na elaboração do portfólio de projetos para os anos de 2012 e 2013 contou, excepcionalmente, com a assessoria de uma empresa contratada para as atividades de comunicação e marketing da organização.

A clareza das prioridades estratégicas por parte dos diretores e colaboradores está fortemente relacionada à questão científica (formação e educação continuada dos médicos associados), como atividade fim da organização. Mas, a relevância estratégica das demais atividades desenvolvidas não é bem dimensionada e, em alguns casos, chega a ser menosprezada. Desse modo, a identificação das informações necessárias para o processo de escolha e definição do portfólio não é aplicada de modo eficaz.

Não é realizada comparação entre os projetos por categorização, mas é considerada a existência de concorrência pelos recursos financeiros. A avaliação dos projetos de acordo com as prioridades estratégicas é discutida com a diretoria executiva, porém, nem sempre isso se concretiza. Esse fato está relacionado à eleição do diretor presidente que é motivada por questões políticas, e não por critérios que considerem outra formação além da medicina e sua capacitação gerencial. Ele escolhe sua diretoria seguindo a mesma linha de raciocínio que o levou ao cargo.

O principal critério adotado para a seleção dos projetos é a valorização que os associados atribuem às linhas de atuação da AME. Para perceber o valor atribuído pelos associados, são realizadas anualmente enquetes nos congressos promovidos pela organização. A partir dos resultados obtidos, são avaliadas as expectativas e prioridades dos projetos, bem como as necessidades de investimentos - em realização e em comunicação - dos mesmos. Todavia, apenas no planejamento dos projetos para o ano de 2013 foi identificada a real utilização desse critério.

Diante dos assuntos e prioridades identificados, e da reavaliação dos projetos desenvolvidos, é realizada a elaboração dos projetos futuros, o levantamento dos custos para execução, análise de viabilidade econômica e de concretização no período de vigência do contrato de patrocínio, além dos benefícios adquiridos pelas empresas parceiras. A definição dos projetos, bem como a aprovação final do portfólio, é feita pela diretoria executiva.

Por fim, é evidente que a organização não adota nenhuma metodologia com embasamento teórico, mas o processo de gestão de portfólio é feito com base na visão da diretoria, tendo em vista alguns indicativos da 
pesquisa com associados, os projetos que têm dado certo ou não e, por vezes, os interesses de pequenos grupos.

A seguir será analisado o processo de seleção de projetos adotado pela AME à luz dos modelos de gestão de portfólio de projetos proposto por Archer and Ghasemzadeh (1999), Rabechini et al. (2005), PMI (2008) e Rocha et al. (2009).

\subsection{Análise à Luz do Modelo de Archer \& Ghasemzadeh}

O modelo proposto por Archer and Ghasemzadeh (1999) para gerenciamento do portfólio de projetos é definido a partir da segmentação do processo em fases e estágios. A análise do processo adotado na organização à luz desse modelo seguirá a fase do processo de seleção do portfólio e seus respectivos estágios, considerados principais pelos autores e que atendem ao objetivo deste estudo, conforme apresentado na Figura 9.

\begin{tabular}{|c|c|c|}
\hline $\begin{array}{l}\text { Fase do } \\
\text { Processo }\end{array}$ & Estágio de Seleção & Análise da Organização Estudada \\
\hline \multirow{5}{*}{$\begin{array}{l}\text { Processo de } \\
\text { Seleção do } \\
\text { Portfólio }\end{array}$} & $\begin{array}{l}\text { Seleção inicial dos projetos rejeitando os } \\
\text { que não atendem aos critérios definidos. }\end{array}$ & $\begin{array}{l}\text { Não tem definição clara e objetiva dos critérios para a seleção } \\
\text { inicial dos projetos. Por meio da aplicação de enquete junto aos } \\
\text { associados, busca-se identificar suas expectativas diante da } \\
\text { atuação da organização, mas nem sempre os resultados são } \\
\text { levados em consideração. A definição do foco estratégico não } \\
\text { possui uma metodologia formal, estruturada e constantemente } \\
\text { aplicada. }\end{array}$ \\
\hline & $\begin{array}{l}\text { Análise individual dos projetos utilizando } \\
\text { cálculos dos parâmetros comuns dos } \\
\text { projetos. }\end{array}$ & $\begin{array}{l}\text { Os projetos são analisados considerando o orçamento para sua } \\
\text { execução, o prazo de realização no período previsto e, por vezes, } \\
\text { pelas intenções políticas da diretoria executiva. Desconhece } \\
\text { qualquer técnica ou metodologia para cálculos e análise do ROI, } \\
\text { VPL ou árvore de decisão. }\end{array}$ \\
\hline & $\begin{array}{l}\text { Seleção dos projetos rejeitando aqueles } \\
\text { que são inviáveis. }\end{array}$ & $\begin{array}{l}\text { Não aplica análise da taxa de retorno, considera o histórico de } \\
\text { projetos realizados, mas não adotada qualquer técnica } \\
\text { padronizada de seleção. }\end{array}$ \\
\hline & $\begin{array}{l}\text { Definição do portfólio aplicando a } \\
\text { verificação de interações, análise dos } \\
\text { atributos e restrições de recursos. }\end{array}$ & $\begin{array}{l}\text { O portfólio é definido, basicamente, considerando o orçamento de } \\
\text { cada projeto, sua execução no período definido, sem planejar a } \\
\text { utilização de outros recursos. Não aplica e desconhece métodos } \\
\text { que auxiliam na tomada de decisão como AHP. }\end{array}$ \\
\hline & $\begin{array}{l}\text { Ajuste do portfólio direcionado aos } \\
\text { usuários. }\end{array}$ & $\begin{array}{l}\text { Não é realizado ajustes ou balanceamento do portfólio levando em } \\
\text { conta seus stakeholders. }\end{array}$ \\
\hline
\end{tabular}

Figura 9. Análise do modelo de Archer \& Ghasemzadeh

Fonte: Elaborado pelos autores.

Segundo Archer and Ghasemzadeh (1999), a seleção de metodologia e o desenvolvimento de estratégias não precisam ser revistos sempre que o portfólio for reavaliado. Contudo, para a organização em análise, que planeja e modifica a cada ano seu portfólio de projetos para captação de patrocínios, torna-se necessária a revisão, principalmente, do foco estratégico.

A análise segundo esse modelo clarifica a falta de métodos objetivos e formais para a seleção inicial dos projetos, causando impacto negativo nas fases seguintes do processo. Para preencher essa lacuna, sugere-se a criação de critérios capazes de auxiliar a tomada de decisão, que poderão ser definidos com a participação de outros departamentos da organização. As técnicas previstas nas fases de análise individual dos projetos e de definição do portfólio (a exemplo de análise do ROI, VPL, etc.), não apresentaram aplicabilidade na organização em estudo, tendo em vista a dificuldade de traduzir os resultados do cálculo dos parâmetros comuns dos projetos em termos monetários.

Portanto, conclui-se que dos cinco estágios de seleção de projetos proposto por esse modelo, quatro são realizados na organização estudada de forma muito superficial, devido à falta de objetividade, formalidade e conhecimento técnico, e um estágio não é realizado.

\subsection{Análise à Luz do Modelo de Rabechini, Maximiano \& Martins}

O modelo para gerenciamento de portfólio de projetos de Rabechini et al. (2005), que foi proposto a partir da aplicação em uma empresa prestadora de serviços, considera seis dimensões: 1) preparação do processo de implementação da gestão de portfólio; 2) identificação de projetos; 3) avaliação; 4) constituição da carteira; 5) administração; 6) revisão e controle. Para aplicação do modelo, os autores levantaram, inicialmente, informações estratégicas e definiram os limites da organização, envolvendo os administradores. A Figura 10 apresenta os resultados da análise das atividades realizadas pela organização caso deste estudo nas quatro primeiras dimensões, visto que as demais são destinadas ao gerenciamento do portfólio e dos próprios projetos.

Para Rabechini et al. (2005) a dificuldade na utilização de um sistema que utiliza critérios ponderados é um ponto de destaque no processo de seleção de projeto. A análise dos resultados da Figura 10 permite corroborar com essa afirmação ao concluir que das quatro dimensões propostas pelo modelo para a seleção de projetos, três não são realizadas pela organização. A única dimensão executada foi de forma muito superficial, 
devido à falta de definição dos riscos e indicadores de sucesso dos projetos, além de não considerar a participação efetiva de outras áreas da organização.

\begin{tabular}{|c|c|c|}
\hline Dimensão & Finalidade & Análise da Organização Estudada \\
\hline $\begin{array}{l}\text { Preparação do processo } \\
\text { de implementação da } \\
\text { gestão de portfólio }\end{array}$ & $\begin{array}{l}\text { Definir critérios ponderados e } \\
\text { estabelecer os respectivos pesos para } \\
\text { avaliação das iniciativas candidatas. }\end{array}$ & $\begin{array}{l}\text { Nenhuma avaliação por critérios e seus respectivos } \\
\text { pesos são utilizados para a avaliação dos projetos } \\
\text { candidatos ao portfólio. }\end{array}$ \\
\hline Identificação de projetos & $\begin{array}{l}\text { Obter uma lista completa de projetos } \\
\text { apresentados pelas áreas da } \\
\text { organização com justificativas } \\
\text { documentadas. }\end{array}$ & $\begin{array}{l}\text { A lista de projetos candidatos é elaborada pelo } \\
\text { departamento de projetos, contemplando apenas } \\
\text { informações dos objetivos e custos de execução. Não } \\
\text { há participação direta de outras áreas da organização. }\end{array}$ \\
\hline Avaliação & $\begin{array}{l}\text { Estabelecer uma lista priorizada de } \\
\text { projetos agregando informações } \\
\text { relevantes e notas. }\end{array}$ & $\begin{array}{l}\text { Nenhum método de avaliação por notas é adotado } \\
\text { para definição de uma lista priorizada de projetos. }\end{array}$ \\
\hline Constituição da carteira & $\begin{array}{l}\text { Constituir um plano de gestão de } \\
\text { portfólio e elaborar regras para a } \\
\text { inserção de novos projetos. }\end{array}$ & $\begin{array}{l}\text { Após a definição e oficialização do portfólio por meio } \\
\text { de contrato com os patrocinadores, não ocorre } \\
\text { exclusão ou inclusão de novos projetos. Portanto, } \\
\text { nenhuma regra para inserção de novos projetos é } \\
\text { adotada. }\end{array}$ \\
\hline
\end{tabular}

Figura 10. Análise do modelo de Rabechini, Maximiano \& Martins

Fonte: Elaborado pelos autores.

\subsection{Análise à Luz do PMI}

A gestão de portfólio, segundo o modelo PMI (2008), possui dois grupos: alinhamento estratégico, e monitoramento e controle. Para atender ao objetivo deste estudo, o foco da análise será o grupo de alinhamento estratégico, que tem a finalidade de garantir a disponibilidade de subsídios necessários para que as metas estratégicas sejam alcançadas por meio do portfólio de projetos. O grupo de processos de alinhamento estratégico está dividido em sete fases: identificação, categorização, avaliação, seleção priorização, balanceamento e autorização. A análise das atividades realizadas em cada fase pela organização é apresentada na Figura 11.

\begin{tabular}{|c|c|c|}
\hline Processo & Objetivo & Análise da Organização Estudada \\
\hline Identificação & $\begin{array}{l}\text { Identificar as informações } \\
\text { necessárias para que a escolha dos } \\
\text { componentes do portfólio seja } \\
\text { definida. }\end{array}$ & $\begin{array}{l}\text { Busca identificar as informações por meio de enquetes, mas não são } \\
\text { sempre utilizadas. A comparação entre os projetos atuais e as novas } \\
\text { propostas considerando as perspectivas futuras não é formalmente } \\
\text { aplicada. }\end{array}$ \\
\hline Categorização & $\begin{array}{l}\text { Categorizar as informações } \\
\text { considerando sua relevância para } \\
\text { o negócio, contribuindo para } \\
\text { avaliação, seleção, priorização e } \\
\text { balanceamento do portfólio. }\end{array}$ & $\begin{array}{l}\text { Não desenvolve a categorização das informações, além de não } \\
\text { considerar sua efetiva contribuição para as relações comerciais e } \\
\text { expectativa dos associados. }\end{array}$ \\
\hline Processo & Objetivo & Análise da Organização Estudada \\
\hline Avaliação & $\begin{array}{l}\text { Avaliar os projetos considerando as } \\
\text { oportunidades e informações } \\
\text { disponíveis. }\end{array}$ & $\begin{array}{l}\text { Nenhuma avaliação por pontuação é utilizada para realização de } \\
\text { comparações entre as oportunidades e projetos, apesar das } \\
\text { prioridades estratégicas serem discutidas com a diretoria executiva. } \\
\text { O principal critério de avaliação adotado é a expectativa dos } \\
\text { associados identificada nas enquetes, mas não é utilizada em todos } \\
\text { os planejamentos. }\end{array}$ \\
\hline Seleção & $\begin{array}{l}\text { Selecionar os projetos tendo como } \\
\text { base a fase de avaliação e os } \\
\text { critérios definidos. }\end{array}$ & $\begin{array}{l}\text { Essa fase não é realizada constantemente, de modo categorizado e } \\
\text { formal, além de refletir a falta de uma melhor aplicação da fase de } \\
\text { avaliação. }\end{array}$ \\
\hline Priorização & $\begin{array}{l}\text { Priorizar os projetos por meio de } \\
\text { categorias estratégica ou } \\
\text { financeira. }\end{array}$ & $\begin{array}{l}\text { Os projetos não recebem classificação que permite análises } \\
\text { posteriores quanto à estratégia. A análise financeira é feita apenas } \\
\text { pelos orçamentos necessários para a execução do projeto. O fator } \\
\text { tempo de execução é considerado na priorização, mas não } \\
\text { constantemente, já que projetos que possuem riscos de não serem } \\
\text { cumpridos no prazo determinado (anualmente) também são } \\
\text { priorizados. }\end{array}$ \\
\hline Balanceamento & $\begin{array}{l}\text { Balancear o portfólio por meio de } \\
\text { um conjunto de projetos } \\
\text { planejados estrategicamente. }\end{array}$ & $\begin{array}{l}\text { Definido o portfólio e sua regulamentação por meio de contrato com } \\
\text { os parceiros, não ocorre exclusão ou inclusão de projetos. Os recursos } \\
\text { financeiros alocados para a realização de cada projeto também não } \\
\text { são reavaliados ou alterados. }\end{array}$ \\
\hline Autorização & $\begin{array}{l}\text { Autorizar e comunicar, } \\
\text { formalmente, a execução ou não } \\
\text { de um projeto, alocando, deste } \\
\text { modo, recursos materiais, } \\
\text { humanos e financeiros. }\end{array}$ & $\begin{array}{l}\text { Os stakeholders são comunicados formalmente quando da execução } \\
\text { dos projetos. Projetos não são cancelados e nem incluídos, com isso, } \\
\text { os recursos financeiros não são realocados. Os projetos são } \\
\text { desenvolvidos pelo departamento de projetos, podendo ser } \\
\text { realocados para outro setor. }\end{array}$ \\
\hline
\end{tabular}

Figura 11. Análise do modelo PMI

Fonte: Elaborado pelos autores. 
A falta de categorização das informações relevantes compromete as relações comerciais diminuindo as oportunidades de efetivação das parcerias, além de não atender às expectativas dos stakeholders, visto que a realização dessa fase causa impacto nas fases seguintes do processo. Desse modo, todos os processos de análise dos projetos, que deveriam estar alinhados estrategicamente, poderão comprometer a definição do portfólio da organização e a captação de recursos financeiros (Rocha et al., 2009; Ruggeri, 2011).

A análise final do processo de seleção de projetos realizado pela Associação segundo esse modelo, que propõe sete processos, permite concluir que apenas quatro processos são realizados, sendo que dois de forma completa e os demais muito superficialmente, decorrentes da falta de categorização e formalidade.

\subsection{Análise à Luz do Modelo de Rocha, Treita, Coutinho \& Farias}

Apesar de ser o único modelo para a gestão de portfólio de projetos direcionado ao terceiro setor identificado na literatura, esse tem maior direcionamento para as empresas que realizam financiamento de projetos, e não para as executoras (como é o caso da organização foco deste estudo). Contudo, a análise com base nesse modelo foi realizada com o intuito de se verificar sua aplicabilidade no processo de definição dos projetos para compor o portfólio da organização em estudo.

O modelo nominado de GPORT, proposto pelos autores Rocha et al. (2009), é definido por três partes principais relacionadas aos níveis operacional, tático e estratégico da organização que avalia os projetos, sendo definidas, respectivamente, pela gerência de projetos, comitê técnico e conselho executivo. É destacada a figura de um administrador responsável pelo gerenciamento e cobrança da realização das atividades de todo o processo. Para facilitar a aplicação do modelo, os autores apresentam uma ferramenta com a finalidade de apoiar a tomada de decisão, tendo também um administrador como o responsável por sua execução.

A figura do administrador na organização foco deste estudo pode ser identificada como sendo o gerente administrativo, mesmo que esse não possua relacionamento hierárquico com o departamento de projetos pelo organograma. Essa relação leva em conta sua posição definida informalmente pela diretoria executiva, e por exercer essa função há mais de 30 anos na organização. A fase inicial do modelo prevê a alimentação da ferramenta com os projetos que farão parte das simulações. Na organização, o cumprimento dessa fase está relacionado com a identificação das informações e expectativas de projetos, adotando-se, por exemplo, a aplicação de enquetes junto aos associados. A Figura 12 apresenta a análise das atividades realizadas pela organização em cada portal.

\begin{tabular}{|c|c|c|}
\hline Portal & Grupos de avaliação & Análise da organização estudada \\
\hline Avaliação Geral & $\begin{array}{l}\text { Os critérios de avaliação correspondem ao nível } \\
\text { operacional, devendo ser desenvolvida e } \\
\text { executada pela gerência de projetos, valendo-se } \\
\text { dos conhecimentos da rotina de projetos nos } \\
\text { processos de pré-avaliações das propostas de } \\
\text { projetos. }\end{array}$ & $\begin{array}{l}\text { O departamento de projetos da organização é } \\
\text { identificado como o responsável pelo cumprimento } \\
\text { desse portal, pois realiza uma primeira avaliação } \\
\text { geral das informações e ideias de projetos. } \\
\text { Contudo, o colaborador desse setor } \\
\text { desempenhava suas funções até } 2011 \text {, sem o } \\
\text { conhecimento específico da metodologia de } \\
\text { projetos. Os critérios de abrangência, orçamento, } \\
\text { capacidade de conclusão, risco e alinhamento aos } \\
\text { objetivos do programa são aplicados parcialmente } \\
\text { e não consecutivos. }\end{array}$ \\
\hline Avaliação Técnica & $\begin{array}{l}\text { Envolve o comitê técnico a nível tático, tem a } \\
\text { responsabilidade em adicionar conhecimentos e } \\
\text { critérios técnicos relativos aos tipos de projetos } \\
\text { que devem estar alinhados ao terceiro setor. }\end{array}$ & $\begin{array}{l}\text { Como na fase anterior, a avaliação técnica } \\
\text { também é exercida pelo departamento de } \\
\text { projetos, podendo contar com a assessoria de } \\
\text { outros setores da organização e da empresa } \\
\text { responsável pela comunicação e marketing. } \\
\text { Parcialmente, e sem definições concretas, os } \\
\text { critérios dessa parte são executados pela } \\
\text { organização na análise do impacto e viabilidade } \\
\text { técnica. }\end{array}$ \\
\hline $\begin{array}{l}\text { Avaliação } \\
\text { Estratégica }\end{array}$ & $\begin{array}{l}\text { Abrange o conselho executivo como nível } \\
\text { estratégico, pois sua função é garantir que os } \\
\text { projetos estejam alinhados de acordo com a } \\
\text { estratégia da organização doadora. }\end{array}$ & $\begin{array}{l}\text { A organização não considera qualquer perfil } \\
\text { estratégico ou de investimentos realizados pelas } \\
\text { patrocinadoras. }\end{array}$ \\
\hline
\end{tabular}

Figura 12. Análise do modelo de Rocha, Treita, Coutinho e Farias

Fonte: Elaborado pelos autores.

Na terceira parte do modelo (avaliação estratégica) está claramente definido que o mesmo é de fato direcionado às organizações financiadoras de projetos e não às executoras. Mas, como a organização em análise define seu portfólio de projetos com a finalidade de alcançar e manter parcerias com a indústria farmacêutica e de produtos médicos para a captação de recursos financeiros, propõe-se que essa fase seja analisada considerando a expectativa dos projetos e o perfil de investimento que as empresas costumam realizar.

A organização pode considerar o histórico dos projetos que contaram com a captação de patrocínios, usar de um instrumento de pesquisa para identificar os projetos de interesse de cada empresa, e nas reuniões que 
antecedem à apresentação do portfólio para o ano seguinte, considerar as ideias e sugestões de melhorias que os representantes das empresas compartilham. Essas considerações estão alinhadas aos critérios propostos na terceira parte desse modelo, que envolve a avaliação da viabilidade estratégica, visibilidade (imagem) e alinhamento estratégico.

A análise final do processo de seleção de projetos realizado pela organização segundo esse modelo que propõe três portais, conclui que dois são realizados de forma parcial e não consecutiva, principalmente pela falta de critérios pré-estabelecidos e formalizados, e um não é executado.

O modelo GPORT apresentou aderência à realidade da organização em estudo, pois considera aspectos específicos do contexto não lucrativo, mesmo sendo direcionado à seleção de projetos por parte das financiadoras. As atividades destinadas ao administrador previstas na fase inicial dessa ferramenta, também poderiam ser desempenhadas pelo departamento de projetos da Associação. Todavia, é necessário que o mesmo possua autonomia de ação para melhor execução das tarefas.

\section{Discussão dos Resultados}

A gestão estratégica da organização é desenvolvida por meio de um planejamento, que objetiva a captação de recursos financeiros para um portfólio de projetos anual, mas não de modo estruturado, apresentando, ainda, variações periódicas decorrentes da mudança constante dos dirigentes. Esse resultado causa reflexo negativo na GPP e, consequentemente, no desempenho da organização (Cooper et al., 1999; Cooper et al., 2001), já que essa deve estar alinhada às estratégias pré-definidas (Castro e Carvalho, 2010b; PMI, 2008), podendo acarretar em redução no volume de patrocínios, perda de competitividade e projetos não realizáveis, como previsto por Rocha et al. (2009) e Ruggeri (2011).

A organização não adota nenhuma metodologia estruturada para a gestão de portfólio de projetos. Os projetos que irão compor o portfólio são selecionados sem critérios formais pré-estabelecidos, destacando-se a falta de engajamento na tomada de decisão da alta direção e gerência. Porém, o apoio dos tomadores de decisão torna-se fundamental para o sucesso da gestão de portfólio (Antunes et al., 2012). Assim, a missão e os objetivos da organização poderão não ser atingidos, uma vez que a seleção dos projetos pode não estar alinhada estrategicamente, impactando, também, no desempenho da organização (Drucker, 2012).

Conforme a análise dos resultados apresentados na seção anterior, a Figura 13 resume a aplicabilidade dos quatro modelos de gestão de portfólio de projetos na AME estudada.

A análise à luz dos quatro modelos possibilitou identificar que não há um modelo totalmente aplicável ao caso estudado, mas algumas fases dos mesmos são contempladas no atual processo de gestão de portfólio adotado pela organização, sendo outras de difícil adequação ao contexto de organizações sem fins lucrativos. Os modelos de Archer and Ghasemzadeh (1999), Rabechini et al. (2005) e PMI (2008), preveem a utilização de metodologias e técnicas não adotadas e desconhecidas pela organização, e dificilmente aplicadas nesse contexto.

Uma análise cuidadosa do modelo GPORT de Rocha et al. (2009), permite corroborar que o mesmo é direcionado, especificamente, para as empresas financiadoras de projetos desenvolvidos por organizações sem finalidade lucrativa. Mas, considerando as adequações propostas no decorrer da análise segundo esse modelo à realidade da organização estudada, ele contribuiu, mesmo que parcialmente, para com o conhecimento das práticas por ela desenvolvidas e das lacunas que necessitam ser preenchidas.

\begin{tabular}{|c|c|c|}
\hline Modelo & Processos & Aplicabilidade na AME estudada \\
\hline $\begin{array}{c}\text { Archer and } \\
\text { Ghasemzadeh } \\
\text { (1999). }\end{array}$ & $\begin{array}{l}\text { Nesse modelo, o processo } \\
\text { de seleção de projetos é } \\
\text { composto por cinco } \\
\text { estágios. }\end{array}$ & $\begin{array}{l}\text { Quatro estágios apresentaram aplicabilidade de modo muito superficial, } \\
\text { considerando a falta de objetividade, formalidade e conhecimento técnico, } \\
\text { e um estágio não é realizado. }\end{array}$ \\
\hline $\begin{array}{l}\text { Rabechini et al. } \\
\text { (2005). }\end{array}$ & $\begin{array}{l}\text { O modelo propõem quatro } \\
\text { dimensões para a seleção } \\
\text { de projetos. }\end{array}$ & $\begin{array}{l}\text { Três dimensões não foram aplicáveis, e apenas uma apresentou } \\
\text { aplicabilidade muito superficial, principalmente, quanto a não definição dos } \\
\text { riscos e indicadores de sucesso dos projetos. }\end{array}$ \\
\hline PMI (2008). & $\begin{array}{lr}\text { Nesse } & \text { modelo, são } \\
\text { propostos } & \text { sete processos } \\
\text { pararárico dos projetos. } & \text { alinhamento } \\
\text { estratégico do }\end{array}$ & $\begin{array}{l}\text { Dois processos são aplicáveis de modo completo e dois muito } \\
\text { superficialmente, devido à falta de categorização e formalidade nas } \\
\text { atividades. }\end{array}$ \\
\hline $\begin{array}{l}\text { Rocha, Treinta, } \\
\text { Coutinho e } \\
\text { Farias (2009). }\end{array}$ & $\begin{array}{l}\text { O modelo sugere três } \\
\text { portais de avaliação de } \\
\text { projetos. }\end{array}$ & $\begin{array}{l}\text { Dois portais apresentam aplicabilidade parcial pela falta de critérios pré- } \\
\text { estabelecidos e formalizados, e um portal não é aplicável. }\end{array}$ \\
\hline
\end{tabular}

Figura 13. Aplicabilidade dos modelos de gestão de portfólio de projetos na seleção de projetos de uma AME

Fonte: Elaborado pelos autores.

Diante da análise do processo de gestão de portfólio da organização caso segundo os quatro modelos, os principais problemas identificados na AME estão relacionados à falta de formalidade dos processos, à ausência de definição e utilização de critérios quantitativos e qualitativos para análise dos projetos, à omissão na categorização dos projetos e ao desconhecimento de qualquer técnica ou método de cálculo de avaliação. Tais 
problemas estão associados à dificuldade de traduzir certos resultados monetários (a exemplo do ROI e VPL), em projetos com finalidades não econômicas, bem como a utilização de critérios ponderados que são de difícil aplicação no processo de seleção de projetos (Archer \& Ghasemzadeh, 1999; Cooper et al., 1999; Rabechini et al., 2005; Rodrigues, 2010). Contudo, a adoção de uma gestão de portfólio de projetos estruturada (Kerzner, 2011), poderá minimizar tais problemas, contribuindo para uma melhor seleção de projetos alinhados aos objetivos estratégicos dessa organização sem fins lucrativos.

O resultado do estudo revela a contribuição e importância da gestão de portfólio para a seleção estratégica de projetos de uma organização. Porém, nas organizações sem fins lucrativos, as técnicas de gestão devem ser adaptadas a esse contexto (Andion, 2005; Mariano \& Rocha, 2011; Oliveira et al., 2005). Os métodos de planejamento estratégicos estruturados ainda são considerados embrionários, impactando na evolução da gestão de portfólio de projetos (Ruggeri, 2011) e, consequentemente, no cumprimento da missão organizacional (Rad \& Levin, 2006).

\section{Considerações Finais}

Este trabalho propôs verificar as práticas desenvolvidas na seleção de projetos de uma Associação Médica Especializada à luz de modelos de gestão de portfólio de projetos. Pode-se afirmar que não há um modelo (entre os quatro analisados) totalmente aplicável, sendo necessário considerar os contextos ambientais e culturais da organização, como preconizados por Hudson (1999) e PMI (2008). Foi possível verificar que a principal dificuldade na gestão de portfólio no caso estudado, envolve as atividades para a seleção de projetos, como previsto por Archer and Ghasemzadeh (1999) e Rabechini et al. (2005).

A adoção formal, estruturada e constante dos critérios de seleção já realizados pela organização, contribuirá para maximizar o processo de seleção estratégica dos projetos e a captação de patrocínios. Também, estará colaborando para o cumprimento da missão organizacional e alcance dos objetivos estratégicos definidos pela diretoria executiva. Recomenda-se, ainda, a participação efetiva dos diretores e de outras áreas da organização para estabelecer uma lista priorizada de projetos, seja a partir das ideias iniciais de novos projetos ou daqueles já existentes. A enquete com associados é uma importante ferramenta de informação, podendo ser usada tanto para o planejamento estratégico, quanto para o processo de seleção de projetos.

Como contribuição acadêmica, este trabalho analisou as práticas da gestão de portfólio de projetos, visto que são considerados incipientes os estudos empíricos com essa abordagem, principalmente no contexto organizacional não lucrativo. Adicionalmente, fica evidente a carência de modelos de gestão de portfólio de projetos adequados para a aplicação em organizações sem fins lucrativos, emergindo a necessidade de estudos para suprir essa lacuna na área de gestão de projetos. Para a sociedade, torna-se relevante por permitir o conhecimento e entendimento da realidade dessas associações ao desenvolverem projetos que causam impactos tanto no âmbito social e político, quanto no econômico.

Para estudos futuros, sugere-se a identificação, na literatura, de outros modelos de gestão de portfólio de projetos para também verificar a aplicabilidade em organizações sem fins lucrativos. Também se indica que tanto os modelos utilizados neste estudo, quanto aqueles que venham a ser identificados, sejam analisados e agrupados num único modelo. Deste modo, tem-se a expectativa de melhor verificação da aplicabilidade dos processos que compõem a gestão de portfólio, considerando os fatores ambientais e culturais do contexto não lucrativo, para a seleção estratégica de projetos.

O estudo tem limitações inerentes à prática de caso único, não admitindo extrapolar os resultados ou generalizá-los. Ainda, limitou-se à análise específica do processo de seleção de projetos, não sendo investigados os demais processos que compõem a gestão de portfólio, a exemplo da revisão e controle. Contudo, finaliza-se com a recomendação de que pesquisadores de gerenciamento de projetos dediquem atenção ao contexto das organizações sem fins lucrativos, no intuito de desenvolver metodologias aplicadas ao setor, que contemplem as características e peculiaridades dessas organizações.

\section{Referências}

Andion, C. (2005). A gestão no campo da economia solidária: particularidades e desafios. Revista de Administração Contemporânea, 9(1), 79-101.

Antunes, P. H., Loos, M. J., \& Miguel, P. A. (2012). Portfólio no desenvolvimento de novos produtos: uma análise das publicações em periódicos nacionais. Revista de Gestão e Projetos, 3(1), 50-71.

Archer, N. P., \& Ghasemzadeh, F. (1999). An integrated framework for project portfolio selection. International Journal of Project Management, 17(4), 207-216.

Carneiro, K. D. A., \& Martens, C. D. P. (2012). Análise da maturidade em gestão de portfólio de projetos: o caso de uma instituição financeira de pequeno porte. Revista de Gestão e Projetos2, 3(1), 252-279.

Castro, H. G. de, \& Carvalho, M. M. de. (2010a). Gerenciamento do portfolio de projetos: um estudo exploratório. Gestão \& Produção, 17(2), 283-296.

Castro, H. G. de, \& Carvalho, M. M. de. (2010b). Gerenciamento do portfólio de projetos (PPM): estudos de caso. Produção, 20(3), 303-321. 
Cooper, R. G., Edgett, S. J., \& Kleinschmidt, E. J. (1998). Best practices for managing R\&D portfolios. Research Technology Management, 41(4), 20-33.

Cooper, R. G., Edgett, S. J., \& Kleinschmidt, E. J. (1999). New product portfolio management: practices and performance. J Prod Innov Management, 16, 333-351.

Cooper, R. G., Edgett, S. J., \& Kleinschmidt, E. J. (2001). Portfolio Management - fundamental to new product success. Product Development Institute, (12), 1-33.

De Maio, A., Verganti, R., \& Corso, M. (1994). A multi-project management framework for new product development. European Journal of Operational ResearchResearch, 78(2), 178-191.

Drucker, P. F. (2012). Administração de organizações sem fins lucrativos: princípios e práticas. (N. Montingelli, Ed.) (1st ed., p. 166). São Paulo: Cengage Learning.

Falconer, A. P. (1999). A promessa do terceiro setor. Centro de Estudos em Administração do Terceiro Setor. Universidade de São Paulo.

Heckert, C. R., \& Silva, M. T. (2008). Qualidade de serviços nas organizações do terceiro setor. Produção, 18(2), 319-330.

Hudson, M. (1999). Administrando organizações do terceiro setor. São Paulo: Makron Books.

Kerzner, H. (2006). Gestão de projetos: as melhores práticas. (L. B. Ribeiro, Ed.) (2nd ed., p. 824). Porto Alegre: Bookman.

Kerzner, H. (2011). Gerenciamento de Projetos: uma abordagem sistêmica para planejamento, programação e controle (10th ed., p. 657). São Paulo: Blucher.

Kruglianskas. (1992). Planejamento do centro de tecnologia empresarial cativo. In: VASCONCELOS, E. (Ed.). Gerenciamento da tecnologia: um instrumento para a competitividade empresarial (pp. 39-96). São Paulo: Edgar Blucher.

Malhotra, N. K. (2006). Pesquisa de Marketing: uma orientação aplicada (4th ed., p. 720). Porto Alegre: Bookman.

Mara, C. M. A. (2000). A strategic planning process for a small nonprofit organization - a hospice example. Nonprofit Management Leadership, 11(2), 211-223.

Mariano, F. A. M., \& Rocha, M. H. P. da. (2011). Profissionalização do terceiro setor, uma excelência para sobrevivência. Estudo de caso de uma organização não governamental. VII Congresso Nacional de Excelência em Gestão. Niterói.

Martins, G. de A., \& Theóphilo, C. R. (2009). Metodologia da investigação científica para ciências sociais aplicadas (2nd ed., p. 247). São Paulo: Atlas.

Oliveira, B., Ross, E. S., \& Altimeyer, H. Y. (2005). Proposta de um modelo de planejamento estratégico para instituições sem fins lucrativos. Revista da FAE, 8(1), 69-80.

PMI, Project Management Institute. (2008). The Standard for Portfolio Management (2nd ed., p. 146). Newton Square.

PMI, Project Management Institute. (2012). Um guia do conhecimento em gerenciamento de projetos: guia PMBOK (4th ed., p. 459). São Paulo: Saraiva.

Rabechini Jr., R., \& Carvalho, M. M. de. (2006). Gerenciamento de projetos na prática: casos brasileiros (1st ed., p. 216). São Paulo: Atlas.

Rabechini Jr., R., Maximiano, A. C. A., \& Martins, V. A. (2005). A adoção de gerenciamento de portfolio como uma alternativa gerencial: o caso de uma empresa prestadora de serviço de interconexão eletrônica. Revista Produção, 15(3), 416-433.

Rad, P. F., \& Levin, G. (2006). Project Portfolio Managment - Tools \& Techiniques. New York: IIL Publishing.

Rocha, F. M., Treinta, F. T., Coutinho, G. F. F., \& Farias, J. R. F. (2009). Gerenciamento de Portfólio: proposta de um modelo adaptado ao Terceiro Setor. XVI SIMPEP (pp. 1-12). Bauru.

Rodrigues, M. C. P. (2010). Retorno econômico de projetos sociais corporativos: limites de avaliação. Instituto para o Desenvolvimento do Investimento Social.

Ruggeri, R. G. (2011). Gerenciamento de projetos no terceiro setor (1st ed., p. 117). Rio de Janeiro: Brasport.

Silveira, R. B. da, Campos, L. M. de S., \& Marcon, R. (2006). A segmentação e a promoção na captação de recursos: um estudo em fundações do terceiro setor. Administração Mercadológica, 5(2), 25-40.

Yin, R. K. (2010). Estudo de Caso: planejamento e métodos. Porto Alegre: Bookman. 